\title{
HUBUNGAN ANTARA DUKUNGAN KELUARGA DENGAN KELENGKAPAN IMUNISASI DASAR DI WILAYAH KERJA PUSKESMAS RANGKASBITUNG DESA CIJORO LEBAK TAHUN 2018
}

\author{
ASSOCIATION BETWEEN FAMILY SUPPORT WITH BASIC \\ IMMUNIZATION COMPLETION IN THE RANGKASBITUNG \\ COMMUNITY HEALTH CENTER AREA OF CIJORO VILLAGE 2018
}

\author{
Nintinjri Husnida, Tutik Iswanti , Ayi Tansah* \\ *Poltekkes Kemenkes Banten \\ Korespondensi: nintinjri.husnida@gmail.com
}

\begin{abstract}
The Millenium Development Goals (MDGs) indicator are reducing child mortality below five years (toddlers) by two-thirds in the number, from 1990 to 2015, meaning reducing child mortality rate from 97 per 1000 live births to 32 per 1000 live births. Followed by health indicators in the 2015 SDGs which is the third goal, namely health insurance and health promotion for all ages. Immunization is an important component to reduce the mortality of children under five years of age. The importance of complete basic immunization is to prevent disability and death in infants/toddlers. The coverage of basic immunizations at the health center is still below the standard of $<90 \%$. The purpose of this study was to analyze the association between family support and completeness of basic immunizations in the Rangkasbitung Public Health Center in Cijoro Lebak Village in 2018. This type of research is quantitative and uses a questionnaire. The number of samples used 48 respondents. The data of this study were taken primarily using a questionnaire. Data analysis to determine the relationship between variables using Chi-Square. Univariate research results indicate the number of mothers with incomplete immunization status. From the bivariate test results, it was found that there is an association between family support and completeness of immunization with an OR value of 6.67. Suggestions for the Rangkasbitung Midwifery Department of Banten health Polytechnic is that this study can be used as a reference in the library and can increase knowledge about basic infant immunization.
\end{abstract}

Keywords : Completeness of Immunization, Family Support

\begin{abstract}
ABSTRAK
Indikator Mellenium Develompent Goals (MDGs) adalah mengurangi kematian anak dengan target menurunkan angka kematian anak di bawah lima tahun (balita) sebesardua per tiga jumlahnya selama periode tahun 1990 sampai dengant ahun 2015 artinya menurunkan dari 97 per 1000 kelahiran hidup menjadi 32 per 1000 kelahiran hidup. Diikuti dengan indikator kesehatan dalam SDGs 2015 yang merupakan goals ketiga yaitu jaminan kesehatan dan promosi kesehatan bagi semua umur. Imunisasi adalah suatu komponen penting untuk menurunkan angka kematian anak usia bawah lima tahun. Pentingnya imunisasi dasar lengkap adalah untuk mencegah kecacatan dan kematian pada bayi / balita. Cakupan imunisasi dasar di Puskesmas sampai saat masih dibawah standar yaitu $<90 \%$. Tujuan dalam penelitian ini adalah untuk menganalisis hubungan antara dukungan keluarga dengan kelengkapan imunisasi dasar di
\end{abstract}


Wilayah kerja Puskesmas Rangkasbitung Desa Cijoro Lebak Tahun 2018. Jenis penelitian ini adalah kuantitatif dan menggunakan kuesioner. Jumlah sampel yang di gunakan 48 responden.Data penelitian ini diambil secara primer menggunakan kuesioner.Analisis data untuk mengetahui hubungan antar variabel menggunakan Chi-Square.

Hasil penelitian univariat menunjukkan jumlah ibu dengan status imunisasi yang tidak lengkap. Dari hasil uji bivariat didapatkan didapatkan bahwa ada hubungan antara dukungan keluarga dengan kelengkapan imunisasi dengan nilai OR 6.67.

Saran untuk Jurusan kebidanan Rangkasbitungagar penelitian ini dapat dijadikan referensi di perpustakaan dan dapat menambah ilmu pengetahuan mengenai imunisasi dasar bayi.

\section{Kata Kunci : Kelengkapan Imunisasi, Dukungan Keluarga}

\section{PENDAHULUAN}

Salah satu indikator Mellenium

tahun 2007 cakupan imunisasi dasar

Develompent Goals (MDGs) adalah

mengurangi kematian anak dengan target

menurunkan angka kematian anak di bawah

lima tahun (balita) sebesar dua per tiga

jumlahnya selama periode tahun 1990

sampai dengan tahun 2015 artinya

menurunkan dari 97 per 1000 kelahiran

hidup menjadi 32 per 1000 kelahiran

hidup.Diikuti dengan indikator kesehatan

dalam SDGs 2015 yang merupakan goals

ketiga yaitu jaminan kesehatan dan promosi

kesehatan bagi semua umur. (WHO, 2008)

Kementerian Kesehatan Indonesia

telah menyusun program sebagai usaha

yang dilakukan untuk menekan penyakit

PD3I pada anak, Seperti Program

Pengembangan Imunisasi (PPI) pada anak

sejak tahun 1956. Keberhasilan bayi dalam

mendapatkan lima jenis imunisasi dasar (HB0, BCG, DPT-HB, Polio, dan Campak) diukur melalui indikator imunisasi dasar lengkap. Data RISKESDAS mencatat, lengkap di Indonesia rata-rata 41,6\%. Kemudian meningkat pada tahun 2010 dengan rata-rata cakupan 53,8 \% . Tahun 2013 rata-rata cakupan imunisasi dasar lengkap kembali meningkat yaitu 59,2\%, sedangkan target Renstra (88\%). (Kemenkes RI, 2015)

Imunisasi adalah suatu upaya untuk menimbulkan / meningkatkan kekebalan seseorang secara aktif terhadap suatu penyakit, sehingga apabila suatu saat terpajan dengan penyakit tersebut tidak akan sakit atau hanya mengalami sakit ringan. Imunisasi pada bayi mengharapkan agar setiap bayi mendapatkan kelima jenis imunisasi dasar lengkap. Keberhasilan seorang bayi dalam mendapatkan 5 jenis imunisasi dasar tersebut diukur melalui indikator imunisasi dasar lengkap. (Kemenkes RI, 2016)

Dampak dari keengganan ibu membawa bayinya ke posyandu untuk 
diimunisasi, adalah peningkatan kerentanan bayi terhadap berbagai penyakit infeksi. Bayi akan mudah terserang penyakit hepatitis B yang berpotensi menimbulkan kanker dan pengerasan hati (sirosis), penyakit polio yang mengakibatkan terjadinya kelumpuhan pada anggota gerak, tuberkulosis (TBC) yang dapat menimbulkan komplikasi berupa meningitis (radang selaput otak), diphtheria (penyakit akut saluran nafas bagian atas) yang dapat merusak jantung, ginjal dan sistem saraf, pertusis (whooping cough) atau lebih dikenal dengan istilah batuk rejan, tetanus, dan campak (measles) yang dapat menimbulkan komplikasi radang telinga tengah, pneumonia, diare serta radang otak (Achmadi, 2006).

Ada beberapa hal yang mempengaruhi belum tercapainya target cakupan imunisasi antara lain rumor yang salah tentang imunisasi, masyarakat berpendapat imunisasi menyebabkan anaknya menjadi sakit, cacat atau bahkan meninggal dunia, pemahaman / pengetahuan masyarakat terutama orang tua yang masih kurang tentang imunisasi, dan motivasi orang tua untuk memberikan imunisasi pada anaknya masih rendah. Black Campaign anti imunisasi saat ini 'gencar' terjadi pada beberapa daerah di Indonesia, baik melalui seminar maupun talkshow anti imunisasi.
Pernyataan ini didukung oleh hasil penelitian Dewi Nur I.S. (2015) yang menyatakan bahwa terdapat hubungan signifikan antara pengetahuan ibu $(\mathrm{p}<0,001)$ dengan kelengkapan imunisasi dasar bayi. (Dewi Nur, 2015).

Selain itu hasil penelitian Adzaniyah, dkk (2014) menyatakan bahwa terdapat hubungan antara tradisi $(\mathrm{p}=0,015)$ dan dukungan keluarga $(\mathrm{p}=0,001)$ terdapat status kelengkapan imunisasi dasar. Penelitian Wirda, dkk (2009) yang menyatakan terdapat hubungan antara dukungan keluarga $(\mathrm{p}=0,000)$ terdapat cakupan imunisasi.

Masalah lain yaitu melalui kegiatan secara umum, mereka melakukan gerakan pula melalui media sosial seperti twitter, facebook, milis, atau blog. Halal-haram vaksin, konspirasi negara barat \& Yahudi, dan efek samping vaksin yang dapat menyebabkan cacat, autisme, atau bahkan kematian menjadi isu utama yang diusung oleh kelompok anti imunisasi ini. Selain itu untuk Puskesmas Rangkasbitung pada tahun 2017 cakupan imunisasi dasar lengkap masih dibawah target yaitu baru mencapai $63 \%$. Sehingga dalam hal ini konseling dari petugas kesehatan juga sangat berpengaruh terhadap cakupan imunisasi dasar.Selain itu Salah satu fenomena yang peneliti rasakan adalah dukungan keluarga yang 
mempengaruhi kelengkapan imunisasi. Tidak sedikit anggota di keluarga yang takut dan beranggapan bawa diimunisasi dapat menyebabkan sakit dan komplikasi.

Berdasarkan uraian dan penelitian terdahulu yang dikemukakan serta fenomena yang terjadi di masyarakat maka peneliti merasa perlu untuk melakukan penelitian tentang “ Hubungan antara dukungan keluarga dengan kelengkapan imunisasi dasar di Wilayah kerja Puskesmas Rangkasbitung Desa Cijoro LebakTahun 2018”.

\section{METODE}

Penelitian ini merupakan penelitian kuantitatif dengan pendekatan cross sectional yang menganalisis mengenai Faktor- faktor yang berhubungan dengan kelengkapan imunisasi dasar di Wilayah kerja Puskesmas Rangkasbitung Desa Cijoro Lebak Tahun 2018”. Populasi target dalam penelitian ini adalah ibu yang memiliki bayi usia 11-12 bulan baik yang sudah mendapatkan imunisasi lengkapo maupun yang belum.

, sedangkan sampel yang digunakan untuk , seclangkan sampel yang digunakan untuk pengambilan data ini sejumlah 53 orang sesuai rumus Slovin untuk tingkat error 5 dan didapatnya jumlah sampel 47 orang .

\begin{tabular}{cccccccc}
$\frac{P}{50}$ & Rendah & 14 & 70.0 & 6 & 30.0 & 20 & 100 \\
\hline Tinggi & 7 & 25.9 & 20 & 74.1 & 27 & 100 \\
\hline TOTAL & 21 & 44.7 & 26 & 55.3 & 47 & 100 \\
\hline \multicolumn{7}{c}{ OR value $=0.007$} \\
\hline
\end{tabular}

Tabel 1 Distribusi frekuensi bayi

\begin{tabular}{lcc}
\hline \multicolumn{1}{c}{ VARIABEL } & F & \% \\
\hline $\begin{array}{l}\text { Kelengkapan } \\
\text { Imunisasi Dasar }\end{array}$ & & \\
\hline Tidak Lengkap & 21 & 44.7 \\
\hline Lengkap & 26 & 55.3 \\
\hline Dukungan Keluarga & & \\
\hline $\begin{array}{l}\text { Dukungan keluarga } \\
\text { rendah }\end{array}$ & 20 & 42.6 \\
\hline $\begin{array}{l}\text { Dukungan keluarga } \\
\text { tinggi }\end{array}$ & 27 & 57.4 \\
\hline
\end{tabular}

Berdasarkan tabel 1 menunjukkan masih ditemukan bayi dengan status imunisasi tidak lengkap sebanyak 21 orang (44.7\%), dukungan keluarga rendah sebanyak 20 orang $(42.6 \%)$.

Tabel 2 Hubungan Dukungan Keluarga Dengan Kelengkapan Imunisasi Dasar Pada Bayi
Dukungan Kelengkapan TOTAL

Keluarga Imunisasi Dasar Tidak Lengkap

\section{HASIL DAN PEMBAHASAN}

Distribusi karakteristik responden dapat dilihat pada tabel 1 berikut ini: 
Hasil analisis hubungan pada tabel 2 menunjukan bahwa imunisasi dasar tidak lengkap lebih banyak (70.0\%) terjadi pada ibu dengan dukungan keluarga rendah dibandingkan dengan ibu dengan dukungan keluarga tinggi (25.9\%).

Secara bivariat diperoleh $\mathrm{P}$ Value $=$ $0.007(\mathrm{P}<\alpha)$ yang berarti terdapat hubungan yang signifikan antara dukungan keluarga dengan kelengkapan imunisasi dasar pada bayi.

Hasil analisis diperoleh nilai $\mathrm{OR}=$ 6.67 yang menunjukan bahwa dukungan keluarga yang rendah memiliki resiko hampir 7 kali lebih besar untuk terjadi ketidaklengkapan imunisasi pada bayi.

\section{Distribusi frekuensi bayi dengan status}

\section{kelengkapan Imunisasi dasar}

Kelengkapan Imunisasi dasar dalam penelitian ini adalah lima imunisasi dasar lengkap yang di canangkan pemerintah meliputi BCG, DPT, Polio, Hepatits B dan Campak.

Dari tabel 1 hasil didapatkan responden dengan status imunisasi yang tidak lengkap $44.7 \%$.Hal ini menunjukkan bahwa cakupan imunisasi masih rendah dan tingkat yang diharapkan. Hasil penelitian lain yaitu penelitian yang pernah dilakukan Rati AP terdapat $38.9 \%$ dari 72 responden dengan status imunisasi yang tidak lengkap.
Hasil penelitian lain yang sejalan adalah penelitian yang pernah dilakukan oleh wati L bahwa dari 40 responden ternyata mayoritas mendapatkan imunisasi bayinya lengkap sebanya 30 responden $(75 \%)$.

Imunisasi merupakan usaha memberika kekebalan pada bayi dengan memasukkan vaksin ke dalam tubuh agar tubuh membuat zat anti untuk mencegak terhadap penyakit tertentu. Dampak dari tidak imunisasi adalah anak tidak mempunyai kekebalan spesiifik, anak akan mudah terserang penyakit berbahaya, system imun anak menjadi lemah, anak akan mudah sakit bahkan kematian atau kecacatan.

Rendahnya kelengkapan imunisasi dari hasil tersebut kemungkinan dipengaruhi beberapa factor.Faktor tersebut dapat berupa pengetahuan Ibu, persepsi, informasi dan dukungan keluarga.Selain itu menurut Makodompit FC penyebab utama rendahnya pencapaian imunisasi dasar lengkap adalah rendahnya kesadaran dan pengetahuan masyarakat tentang imunisasi, manfaat imunisasi, jadwal pemberian, informasi serta gejala pasca imunisasi. Selain itu factor ketersediaan fasilitas kesehatan serta kondisi social ekonomi juga ikut mempengaruhi rendahnya pencapaian Universal Child Immunization (UCI). 
Upaya yang dapat dilakukan untuk meningkatkan status kelangkapaan imunisasi bayi adalah dengan meningkatkan kesadaran masyarakat melalui penyuluhan agar menambah pengetahuan masrakat menjadi baik, sehingga menimbulkan perubahan perilaku ke arah yang baik, menimbulkan persepsi positif ibu untuk mengimunisasi bayi dan mengajak keluarga agar mendapat dukungan penuh serta pengaruh yang baik tentang asumsi pemberian imunisasi.

\section{Hubungan antara dukungan keluarga} ibu terhadap kelengkapan imunisasi dasar

Dukungan keluraga yang dimaksud dalam penelitian ini adalah dukungan yang diberikan oleh anggota keluarga (suami, istri dan saudara) sehingga individu yang diberikan dukungan merasakan bahwa dirinya diperhatikan, dihargai, dan mendapatkan bantuan dari orang-orang yang berarti serta memiliki ikatan keluarga yang kuat dengan anggota keluarga lain.

Pada hasil didapatkan responden yang mendapatkan dukungan keluarga rendah sebesar $42.6 \%$. Hasil ini sejalan dengan penelitian yang pernah dilakukan Ritong MRS dkk, yaitu terdapat $12.5 \%$ responden dengan dukungan informasional yang kurang patuh melkasanakan imunisasi dasar .
Dengan adanya hasil tersebut maka memungkinkan ibu yang tidak mendapatkan dukungan keluarga akan cenderung tidak membawa bayinya untuk imunisasi.

Berdasarkan hasil uji Chi-Square menunjukkan hasil uji $(\mathrm{P}<\alpha) \mathrm{P}=0.007$ yang berarti ada hubungan yang signifikan antara dukungan keluarga terhadapan kelengkapan imunisasi. Hasil yang sama dinyatakan oleh Ritong MRS dkk, yaitu ada hubungan dukungan informasional terhadap kepatuhan ibu dalam melaksanakan imunisasi dasar pada anak.

Hasil analisis juga diperoleh nilai $\mathrm{OR}=6.67$ yang menunjukan bahwa dukungan keluarga yang rendah memiliki resiko hampir 7 kali lebih besar untuk terjadi ketidaklengkapan imunisasi pada bayi.

Hasil penelitian lain yang pernah dilakukan Azahra Yuni dan Susanti SJ adalah dukungan penilaian keluarga terhadap ibu dalam melaksanakan imunisasi pada balita di Aceh bahwa sebagian besar berada pada kategori tinggi

Terdapatnya hubungan pada penelitian ini diasumsikan bahwa dukungan yang diberikan oleh anggota keluarga (suami, istri, dan saudara) akan memberikan respon pada ibu yaitu ibu merasa sebagai individu yang diperhatikan, dihargai dan mendapatkan bantuan dari orang-orang yang berarti serta memiliki ikatan keluarga 
yang erat. Dengan kata lain ibu yang mendapatkan dukungan akan cenderung memperhatikan bayinya untuk dilakukan imunisasi.

Adapun upaya yang dapat dilakukan pada keluarga yang kurang mendapatkan dukungan dapat dilakukan melalui kerjasama tenaga kesehatan, tokoh agama dan tokoh masyarakat dalam meningkatkan dukungan penilaian keluarga . Tenaga kesehatan dapat berperan sebagai konseling (counselor) yaitu membantu keluarga dalam meilih solusi atau mengatasi masalah yang sedang dihadapi. Sehingga keluarga dapat memandang betapa pentingnya imunisasi dari segi kesehatan untuk bayi / balitanya.Sedangkan tokoh agama dan tokoh masyarakat dapat memberikan pandangan bahwa imunisasi sangat penting manfaatnya serta halal menurut pandangan hukum. Dengan demikian makin makin tinggi pula keikutsertaan ibu terhadap imunisasi pada bayi.

\section{SIMPULAN}

Berdasarkan hasil penelitian maka dapat disimpulkan:

1. Distribusi frekuensi bayi dengan status kelengkapan imunisasi dasar di Wilayah kerja Puskesmas Rangkasbitung Desa Cijoro Lebak Tahun 2018 sebesar 55,3
$\%$ dengan status imunisasi dasar lengkap.

Terdapat hubungan dukungan keluarga ibu terhadap kelengkapan imunisasi dasar di Wilayah kerja Puskesmas Rangkasbitung Desa Cijoro Lebak Tahun 2018 dengan nilai OR 6,67.

\section{UCAPAN TERIMAKASIH}

Ucapan terima kasih penulis kepada para ibu balita di Desa Cijoro Rangkasbitung yang telah berpartisipasi dalam penelitian ini. Terima kasih juga kami ucapkan kepada pihak Puskesmas Rangkasbitung Desa Cijoro Lebak . Poltekkes Kemenkes Banten yang telah memberikan dukungan atas penelitian ini.

\section{DAFTAR RUJUKAN}

Achmadi.2006. Imunisasi mengapa perlu. Jakarta; Cetakan I Penerbit Karya .

Adzania M, 2014, Merawat Balita Muda. Bandung: Nex Media Inc

Azzahra Y dan susanti SS, 2017. Dukungan keluarga terhadap Ibu dalam melaksanakan imunisasi pada balita .(online)(Diakses 2 oktober 2018) pada

https://media.neliti.com/media/publi cations/14357-ID-hubungan-antaradukungan-keluarga-terhadapkepatuhan-ibu-melaksanakanimunisasi.pdf

Kemenkes RI Tahun 2015 tentang Profil Kesehatan Indonesia. Jakarta. 
Kemenkes RI Tahun 2016 tentang Buku Ajar Imunisasi cetakan III. Jakarta.

Mokodompit FC. Faktor-faktor yang berhubungan dengan status imunisasi dasar lengkap pada bayi di wilayah kerja puskesmas tungoi kabupaten bolaang mongondow.(online)(Diakses 4 oktober 2018) pada .http://jkesmasfkm.unsrat.ac.id/wpcontent/uploads/2015/06/2-FIX-

FUNDHORA-C.MOKODOMPIT.pdf

Nur Dewi IS dkk.2015 Hubungan pengetahuan ibu tentang imunisasi dasar dengan kelengkapan imunisasi dasar bayi di wilayah Kerja Puskesmas Bendo Kabupaten magetan. Naskah publikasi skripsi universitas muhammadiyah . Surakarta. (online)(Diakses 2 oktober 2018) pada file:///C:/Users/KEBIDANAN/Dow nloads/2910-6076-1-SM.pdf

Rati AP. 2015.Analisis faktor - faktor yang mempengaruhi kelengkapan Imunisasi dasar lengkap pada batita usia 99-24 buloan di desa pal IX kecamatan sungai kakap kabupaten kubu raya. Diunduh tanggal 6 Oktober 2018. Diakses di http://jurnal.untan.ac.id/index.php/j mkeperawatanFK/article/viewFile/1 $\underline{0783 / 10306}$

Ritonga MRS dkk. 2014. Hubungan antara dukungan keluarga terhadap kepatuhan Ibu melaksanakan imunisasi dasar pada anak di desa tigabolon kecamatan sidamanik kabupaten simalungun tahun 2014. (online) (Diakses 2 oktober 2018) pada

https://media.neliti.com/media/publi
cations/14357-ID-hubungan-antaradukungan-keluarga-terhadapkepatuhan-ibu-melaksanakanimunisasi.pdf

Suharsaputra U (2012). Metodologi penelitian kuantitatif, kualitatif dan tindakan. Jakarta: Refika Aditama.

Wati L. 2013. Hubungan pengetahuan, pendidikan dan informasi ibu dengan kelengkapan imunisasi dasar pada anak 1-5 tahun di puskesmas titue. (online)(Diakses 10 oktober 2018) pada http://simtakp.stmikubudiyah.ac.id WHO Tahun 2008. Millenium Development goals (MDGs). Jakarta; United Nation 